\title{
Trace gas transport in the 1999/2000 Arctic winter: comparison of nudged GCM runs with observations
}

\author{
M. K. van Aalst ${ }^{1}$, M. M. P. van den Broek ${ }^{2}$, A. Bregman ${ }^{3}$, C. Brühl ${ }^{4}$, B. Steil ${ }^{4}$, G. C. Toon ${ }^{5}$, S. Garcelon ${ }^{6}$, \\ G. M. Hansford ${ }^{6}$, R. L. Jones ${ }^{6}$, T. D. Gardiner ${ }^{7}$, G. J. Roelofs ${ }^{1}$, J. Lelieveld ${ }^{4}$, and P. J. Crutzen ${ }^{4}$ \\ ${ }^{1}$ Institute for Marine and Atmospheric Research (IMAU), Utrecht, The Netherlands \\ ${ }^{2}$ Space Research Organisation of the Netherlands (SRON), Utrecht, The Netherlands \\ ${ }^{3}$ Royal Netherlands Meteorological Institute (KNMI), De Bilt, The Netherlands \\ ${ }^{4}$ Max Planck Institut für Chemie (MPI), Mainz, Germany \\ ${ }^{5}$ Jet Propulsion Laboratory (JPL), Pasadena, CA, USA \\ ${ }^{6}$ Cambridge University, Cambridge, UK \\ ${ }^{7}$ National Physical Laboratory (NPL), Teddington, UK
}

Received: 4 March 2003 - Published in Atmos. Chem. Phys. Discuss.: 15 May 2003

Revised: 13 January 2004 - Accepted: 19 January 2004 - Published: 23 January 2004

\begin{abstract}
We have compared satellite and balloon observations of methane $\left(\mathrm{CH}_{4}\right)$ and hydrogen fluoride (HF) during the Arctic winter 1999/2000 with results from the MAECHAM4 middle atmospheric general circulation model (GCM). For this purpose, the meteorology in the model was nudged towards ECMWF analyses. This nudging technique is shown to work well for this middle atmospheric model, and offers good opportunities for the simulation of chemistry and transport processes. However, caution must be used inside the polar vortex, particularly late in the winter. The current study focuses on transport of $\mathrm{HF}$ and $\mathrm{CH}_{4}$, initialized with satellite measurements from the HALOE instrument aboard the UARS satellite. We have compared the model results with HALOE data and balloon measurements throughout the winter, and analyzed the uncertainties associated with tracer initialization, boundary conditions and the passive tracer assumption. This comparison shows that the model represents some aspects of the Arctic vortex well, including relatively small-scale features. However, while profiles outside the vortex match observations well, the model underestimates HF and overestimates $\mathrm{CH}_{4}$ concentrations inside the vortex, particularly in the middle stratosphere. This problem is also evident in a comparison of vortex descent rates based upon vortex average tracer profiles from MA-ECHAM4, and various observations. This could be due to an underestimate of diabatic subsidence in the model, or due to too much mixing between vortex and non-vortex air.
\end{abstract}

Correspondence to: $\mathrm{M} . \mathrm{K}$. van Aalst

(aalst@phys.uu.nl)

\section{Introduction}

The Arctic winter stratosphere is one of the main areas of interest regarding the effects of increasing greenhouse gas concentrations on the middle atmosphere. The northern polar vortex is generally less stable and more disturbed than its southern counterpart. Consequently, the low temperatures that are necessary for the formation of polar stratospheric clouds and activation of chlorine that leads to ozone loss in spring occur less frequently, and a large-scale ozone hole is restricted to the Antarctic stratosphere. However, in the 1990s, there have been several very cold Arctic winters, including 1994-1995, 1995-1996, and 1996-1997. The 19992000 winter studied here exhibited the lowest average temperatures on record (Manney and Sabutis, 2000), and extensive denitrification and ozone destruction took place (e.g. Rex et al., 2002). At the same time, some model studies have shown that increasing greenhouse gas concentrations may indeed cause an increase in the stability of the vortex, and a decrease of polar middle atmospheric temperatures, resulting in enhanced ozone loss (e.g. Shindell et al., 1998, 1999; Austin et al., 2003).

To improve our understanding of these phenomena and the reliability of predictions for future ozone loss, it is crucial that climate models represent the polar vortex, and the transport of reactive species inside it, realistically. In particular, we want to test our middle atmospheric general circulation models (GCMs), so that they can be used, with fully coupled chemistry, to simulate the future composition and climate of the middle atmosphere. However, by their very nature, these climate models do not reproduce the weather in any particular period of which we may have detailed measurements. 
Hence, we can only validate their performance by assessing mean state and variability over a reasonably long time period in which sufficient observations are available. Many of the processes in climate models however, such as some of the middle atmospheric chemistry-climate interactions that are at play in polar ozone destruction, occur on much shorter time scales. Moreover, we often lack the observational record for proper validation.

To overcome some of these difficulties, we have applied, for the first time, a relaxation technique ("nudging") to a middle-atmospheric GCM. By adding small additional tendencies, which hardly disturb the model's inherent physical consistency, we continuously adjust the model towards actual meteorological conditions (Jeuken et al., 1996). In this way, the model can be compared with instantaneous observations that depend on the actual meteorological situation. Once tested with respect to processes on relatively short timescales, the GCM can be left free again to study longer-term changes associated with different atmospheric conditions. Such nudging techniques have been used extensively for tropospheric studies (e.g. de Laat et al., 1999), but not for the middle atmosphere. Until recently, the observational data to be assimilated into the model, provided by the ECMWF, were only available up to $10 \mathrm{hPa}$. Since March 1999 however, a new version of the ECMWF model is operational, with a new vertical resolution, and extended upwards to $0.2 \mathrm{hPa}$, equivalent to about $70 \mathrm{~km}$. Using these meteorological data, which are referred to as operational data (OD), we have applied this same technique in our middle atmospheric GCM. Once they are available, we will also be able to employ data from the ERA-40 reanalysis, which will provide data with the same model top for the entire period from 1957 to 2001 (see http://wms.ecmwf.int/research/era/index.html).

In this study, we have applied the nudging technique to test tracer transport in our MA-ECHAM4 model during the Arctic winter 1999/2000. Related transport studies with the same model include a report by Manzini and Feichter (1999), who evaluated the large-scale transport in MA-ECHAM4 by examining sulphur hexafluoride $\left(\mathrm{SF}_{6}\right)$ concentrations in a 15year integration. They showed that the model reproduced an appropriate evolution and distribution of this passive tracer, and that the mean age of air and transport barriers in the model compared favorably to observations and theory. In addition, results from the MA-ECHAM4 model have been included in several stratospheric model intercomparisons, e.g. by Koshyk et al. (1999) and Pawson et al. (2000). The MAECHAM4 model has also been used for coupled climatechemistry studies (Steil et al., 1998, 2003; Manzini et al., 2003), including investigations of the effect of changing atmospheric conditions on polar dynamics and chemistry. That model version, which includes the CHEM chemical module, has also been evaluated in a model intercomparison by Austin et al. (2003).

In addition, many studies have discussed stratospheric transport of trace gases in middle atmospheric chemistry transport models (CTMs), and show than substantial challenges remain. For instance, Hall et al. (1999) showed that two- and three-dimensional chemistry transport models differed markedly in their performance in relation to the age of air and the propagation of annual oscillations in tracer mixing ratios at the tropical tropopause (the tape recorder effect). Some of these problems may be related to advection schemes, the horizontal and vertical resolution, or the meteorological input data for the transport schemes, including the processing of those data for use in transport schemes (e.g. Bregman et al., 2003). Another possible cause for discrepancies, first recognized by Chipperfield et al. (1997), could be the formulation of the vertical coordinate. Recently, Mahowald et al. (2002) presented results from IMATCH, a new version of the MATCH model that uses hybrid-isentropic coordinates, which are terrain following near the surface (like most models), but switch to isentropic levels from the upper troposphere on. They show that this model version is better able to capture the observed age of air distribution and water vapor transport than the regular hybrid-pressure MATCH model, apparently due to the lower numerical vertical diffusion in IMATCH in the lower tropical stratosphere region. Looking more specifically at the Arctic vortex in 1999-2000, Ray et al. (2002) showed that both descent and mixing are required to properly reproduce observed longlived tracer-tracer correlations. Based on simple calculations of changing correlations under different assumptions of the mixing processes occurring within the vortex or between vortex and midlatitude air, they conclude that differential descent and subsequent mixing within the vortex best reproduces the observed correlations. Plumb et al. (2002) found, based on comparisons of modeled $\mathrm{N}_{2} \mathrm{O}$ with observations throughout the winter, that their model $(\mathrm{MATCH})$ overestimated $\mathrm{N}_{2} \mathrm{O}$ in the lower stratospheric vortex, due to an excess of inner-vortex mixing or an overestimate of transport across the vortex boundary. Greenblatt et al. (2002) however, found that vortex descent rates calculated by SLIMCAT and REPROBUS agreed reasonably well with observations.

To assess how our GCM is performing with respect to these transport challenges, we have compared model output with observations in that same Arctic winter 1999/2000, which was well studied by the Third European Stratospheric Experiment on Ozone (THESEO) and the Stratospheric Aerosol and Gas Experiment III (SAGE III) Ozone loss and Validation Experiment (SOLVE) campaigns. We have compared model results with satellite and balloon measurements of hydrogen fluoride (HF) and methane $\left(\mathrm{CH}_{4}\right)$, two tracers with relatively long chemical lifetimes that can be used as passive tracers of motion, particularly in the lower stratosphere (e.g. Brasseur and Solomon, 1986). The reverse distribution of sources and sinks of $\mathrm{HF}$ and $\mathrm{CH}_{4}$ implies that they have roughly opposite vertical profiles, HF monotonically increasing with altitude, and $\mathrm{CH}_{4}$ monotonically decreasing. $\mathrm{CH}_{4}$ is emitted at the surface, and broken down mainly at higher altitudes by reaction with $\mathrm{OH}, \mathrm{O}^{1} \mathrm{D}$ and $\mathrm{Cl}$ 
radicals, and, above the stratopause, by photolysis. Its average lifetime is more than 30 years at an altitude of $20 \mathrm{~km}$, decreases to about three months at $45 \mathrm{~km}$, rises again to a few years at $65 \mathrm{~km}$, and then decreases to a few days above $80 \mathrm{~km}$ (Brasseur and Solomon, 1986). The use of HF as a tracer of stratospheric motion has been discussed extensively by Chipperfield et al. (1997). It originates in the middle and upper stratosphere as an end product of the fluorine that is released in the dissociation of CFCs. Once produced, it is very inactive, with tropospheric rainout as the only significant removal process. Its production timescale is of the same order as the dissociation timescale of CFCs (a combination of the local photochemical destruction timescale and the overturning timescale that provides "fresh" CFCs). In this study, HF and $\mathrm{CH}_{4}$ were initialized with HALOE data in early September and then advected throughout the Arctic winter. On this timescale, $\mathrm{CH}_{4}$ destruction and HF production may cause the passive tracer assumption to break down, particularly in the upper stratosphere and mesosphere. Moreover, these sources and sinks may also affect concentrations lower down, particularly when downward transport is relatively strong, such as in the winter polar vortex. We have tested the sensitivity of our results to these effects by including appropriate upper boundary conditions, emissions and rainout, as well as approximate 2-dimensional $\mathrm{CH}_{4}$ loss rates, and comparing these results with purely passive tracer simulations. Based upon the same initialization and constraints as presented in this study, van den Broek et al. (2003), using the TM5 "zoom"-CTM, have assessed the effect of horizontal resolution on the representation of tracer transport.

Section 2 of this paper describes the measurements (satellite and balloon data) that we use for this comparison. Section 3 introduces our model and the nudging procedure, and Sect. 4 the experiment setup. Section 5 presents a brief overview of the conditions in the Arctic winter 1999/2000, as an introduction to Sect. 6 which presents the results of our model runs and a comparison with the data. Section 7 is a discussion of the findings, leading into the conclusion (Sect. 8).

\section{Measurements}

\subsection{HALOE}

Data from the Halogen Occultation Experiment (HALOE) were used for both the initialization of the tracer fields in our model, and for comparison with model data later in the winter. HALOE was launched on the Upper Atmosphere Research Satellite (UARS) spacecraft in September 1991. It is a solar occultation experiment, which uses wide band and gas cell correlation radiometry techniques in several infrared wavebands to measure vertical profiles of $\mathrm{O}_{3}, \mathrm{HCl}, \mathrm{HF}, \mathrm{CH}_{4}$, $\mathrm{H}_{2} \mathrm{O}, \mathrm{NO}, \mathrm{NO}_{2}$, aerosol extinction, and temperature versus pressure, providing a vertical resolution of about $2 \mathrm{~km}$. More details about the experiment and its instruments are provided by Russell et al. (1993). HALOE measures a set of 15 sunset profiles and 15 sunrise profiles every day, each set positioned around the earth along one latitude band (one on the northern and one on the southern hemisphere). HALOE's line of sight moves from south to north (or vice-versa) in monthly "sweeps", providing coverage of almost the whole globe, except over the two polar caps. Given the long polar nights, HALOE coverage of the polar vortex is limited to the instances when the vortex is elongated and/or off-center, so that part of it crosses the most poleward latitudes covered by HALOE. In our Arctic winter, such observations were available, among others, in early December (at about $47^{\circ} \mathrm{N}$ ) and late February (at about $56^{\circ} \mathrm{N}$ ).

In this study we have used level 2, version 19 data, available at the HALOE website (http://haloedata.larc.nasa.gov). The validation of HALOE HF data is described by Russell et al. (1996). HF measurements were shown to match balloon observations to within $7 \%$ throughout the stratosphere above $70 \mathrm{mbar}$, at a precision smaller than $0.04 \mathrm{ppbv}$ between the tropopause and the stratopause. Luo et al. (1994) gave a detailed description of the stratospheric HF distribution, based upon the new global HALOE measurements, comparisons with previous measurements, and the NCAR 2D model. The validation of HALOE $\mathrm{CH}_{4}$ data is described by Park et al. (1996). The estimated total error in the $\mathrm{CH}_{4}$ concentrations is about $7 \%$ between 12 and $40 \mathrm{~km}$; the precision is about $0.1 \mathrm{ppmv}$ at $16 \mathrm{~km}$, going down to values smaller than $0.05 \mathrm{ppmv}$ between 25 and $75 \mathrm{~km}$. For altitudes below $35 \mathrm{~km}$, the HALOE retrieval of chemical data uses pressures from NCEP assimilated meteorology. Between 35 and $85 \mathrm{~km}$, pressure is retrieved from the $2.8 \mu \mathrm{m} \mathrm{CO}_{2}$ band (Russell et al., 1993).

\subsection{Balloon data}

The HALOE measurements described above have the general advantage of good spatial and temporal coverage and a large altitude range. Moreover, it is relatively straightforward to compare HALOE measurements with our model data, which result from an initialization with data of the same origin. However, HALOE's coverage is not optimal for observing the polar vortex, and its vertical resolution is limited relative to in-situ instruments. To circumvent these limitations, we have also included comparisons with measurements of the TDLAS and MkIV balloon-borne instruments that were deployed from Esrange $\left(68^{\circ} \mathrm{N}, 21^{\circ} \mathrm{E}\right)$, near Kiruna, Sweden, in the framework of THESEO 2000 and SOLVE.

The near-infrared Tunable Diode Laser Absorption Spectrometer (TDLAS) from the UK National Physical Laboratory and University of Cambridge performs in-situ measurements of $\mathrm{CH}_{4}$, at relatively high frequency (about every $2.3 \mathrm{~s}$ ) and thus high vertical resolution (which of course depends upon the vertical speed of the balloon, but ranges from about $0.5 \mathrm{hPa}$ in the troposphere to less than $0.1 \mathrm{hPa}$ towards the 
Table 1. Nudging settings, for the four nudged model variables.

\begin{tabular}{ll}
\hline Prognostic variable & Nudging strength $G\left(\mathrm{~s}^{-1}\right)$ \\
\hline Temperature & $1 \times 10^{-5}$ \\
Divergence & $5 \times 10^{-5}$ \\
Vorticity & $10 \times 10^{-5}$ \\
Surface pressure & $10 \times 10^{-5}$ \\
\hline
\end{tabular}

end of the flight, between 10 and $15 \mathrm{hPa}$ ). The instrument is calibrated prior to flights using gas standards, with a concentration accuracy of $1 \%$. The estimated absolute accuracy and the detection limit are $10 \%$ and a few ppbv, respectively. The TDLAS was deployed aboard the Systme d'Analyses par Observations Zénitales (SAOZ) platform on several days in the SOLVE/THESEO winter, including 28 January (inside the vortex; the instrument experienced a problem at the beginning of this flight, so data below about $78 \mathrm{hPa} / 407 \mathrm{~K}$ should be treated with caution), 9 February (outside the vortex), 13 February (inside the vortex, close to the edge), 27 February (inside the vortex, close to the edge) and 25 March 2000 (after a vortex breakup episode, outside the vortex remnants).

The MkIV Interferometer from the Jet Propulsion Laboratory (JPL) is a Fourier Transform Infra-Red (FTIR) Spectrometer (e.g. Toon, 1991). It is a remote sensing instrument, using solar occultation absorption spectroscopy in the wavelength range of 1.77 to $15.4 \mu \mathrm{m}$ to measure a number of trace gases, including both $\mathrm{HF}$ and $\mathrm{CH}_{4}$, with a vertical resolution of about $2 \mathrm{~km}$ (Toon et al., 1999). MkIV has been deployed on a number of aircraft and balloon missions since 1984, and has also been used extensively as a ground-based instrument. During the SOLVE/THESEO winter, MkIV was flown as part of the Observations of the Middle Stratosphere (OMS) payload on 3 December, 1999 and 15 March 2000 (both inside the vortex, at the latter date with substantial midlatitude air mixed in at higher altitudes).

\section{Model description}

\subsection{MA-ECHAM4}

MA-ECHAM4 is the middle atmospheric version of the ECHAM4 general circulation model. It has a hybrid-pressure vertical coordinate system with 39 levels and a model top at $0.01 \mathrm{hPa}$. A description of the ECHAM4 model can be found in Roeckner et al. (1996), and details of MA-ECHAM4 are given by Manzini and McFarlane (1998) and Manzini et al. (1997). Both versions have the same basic model structure and also share most of the physical parameterizations. The main dynamical calculations are performed in spectral space, while tracer transport is calculated with a semi-Lagrangian advection scheme (Rasch and Williamson, 1990; Rasch et al., 1995). Aside from some modifications in the radiation scheme and horizontal diffusion, MA-ECHAM4's main difference with ECHAM4 is the gravity wave parameterization. This parameterization is discussed by Manzini and McFarlane (1998), and includes a modified version of the McFarlane (1987) parameterization for the orographic gravity wave drag and a Doppler spread formulation of Hines $(1997 \mathrm{a}, \mathrm{b})$ to parameterize the effects of the broadband gravity wave spectrum. In this study, we have used MA-ECHAM4 at spectral triangular truncation $\mathrm{T} 42$, which corresponds to a horizontal resolution of about $2.8^{\circ} \times 2.8^{\circ}$. The time step was $900 \mathrm{~s}$; full radiation calculations were performed every 8 timesteps.

\subsection{Nudging procedure}

To ensure that the model represents actual meteorological conditions during the period under investigation, we have used a four-dimensional assimilation technique (nudging), based upon simple Newtonian relaxation. A more detailed description of this "nudging" procedure, applied in the regular version of the ECHAM4 model, is given by Jeuken et al. (1996). Essentially, the model is nudged toward the observed state by adding a nonphysical tendency to the overall tendency of a prognostic model variable:

$d X / d t=F_{m}(X)+G(X) \times\left[X_{o b s}-X\right]$.

$X$ can be any prognostic model variable (in this study we nudge surface pressure, divergence, vorticity, and temperature). $F_{m}(X)$ is the model forcing for variable $X, G(X)$ the relaxation coefficient $\left(\mathrm{s}^{-1}\right)$, and $\left[X_{o b s}-X\right]$ the difference between model and the observations. To some extent, the relaxation coefficient $G$ can be chosen freely. However, if $G$ is too small, the model will not be influenced by the observations. On the other hand, if $G$ is chosen too large, the model may deviate too far from its own balanced state, leading to artificial responses to these unbalanced tendencies. We have adopted the optimal nudging settings from Jeuken et al. (1996) (see Table 1), who performed sensitivity tests on the nudging strength of these four variables and showed that the model output depends only very weakly on the exact choice of $G$, particularly in the extratropics. We have checked that the nudging tendencies are generally significantly smaller than the model's own physical tendencies, in both the lower and middle atmosphere.

The prognostic variables are relaxed toward the 6-hourly operational ECMWF data, which are produced for weather forecasting purposes. We note that we thus do not nudge towards actual observations (such as data from meteorological stations across the world, as well as satellites) but towards the ECMWF output, in effect an interpolation of a manifold of observations through an advanced data assimilation process that takes into account, for instance, the accuracy of the various observations. On 9 March 1999, the ECMWF deterministic forecasts switched to a 50 level model version extending to $0.2 \mathrm{hPa}$. From 12 October 1999 on, the 

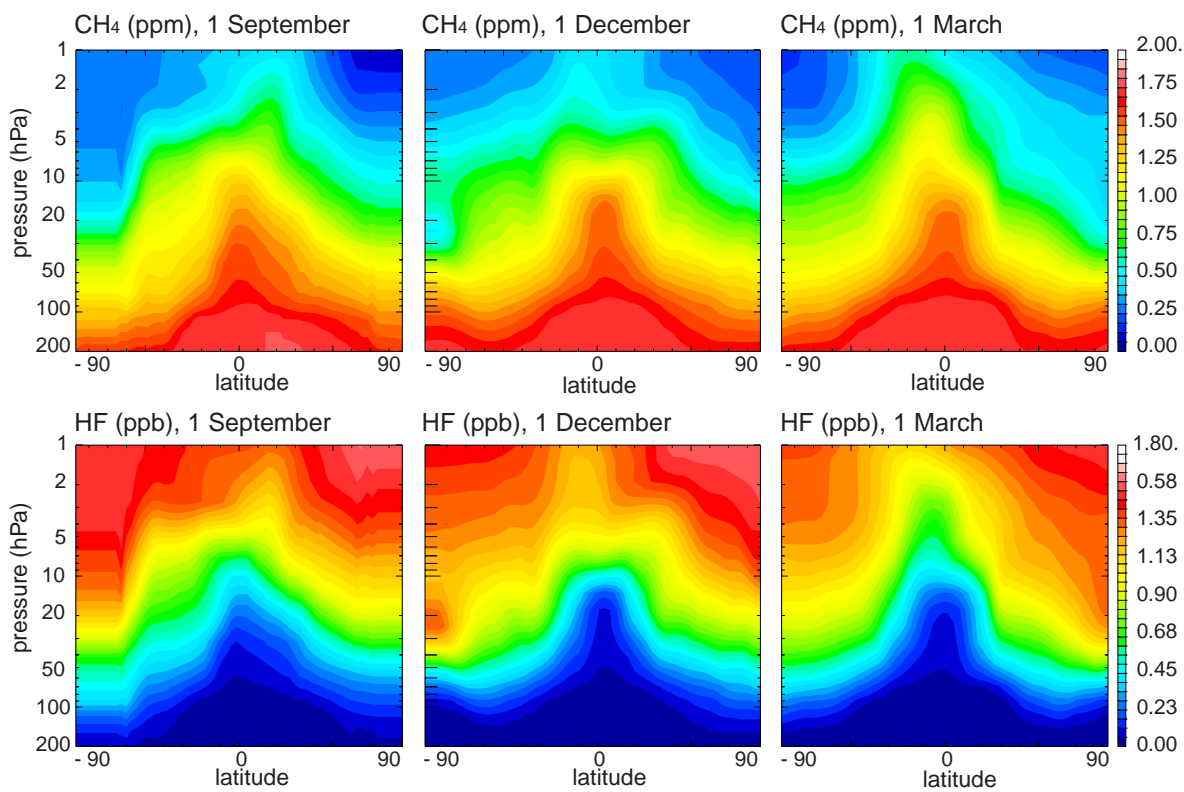

Fig. 1. Latitude versus pressure (from 200 to $1 \mathrm{hPa}$ ) zonal mean cross-sections of MA-ECHAM4 $\mathrm{CH}_{4}$ and $\mathrm{HF}$ fields on $1 \mathrm{September}$ (initialization), 1 December and 1 March.

vertical resolution was increased to 60 levels. To match MAECHAM's vertical coordinate system and orography, a sophisticated vertical interpolation of nudging data was performed by the INTERA package (Ingo Kirchner, personal communication). In this study, no nudging was applied to the top three MA-ECHAM4 levels, which lie at or above the highest ECMWF pressure level. Some caution is also required regarding the highest altitudes represented in the ECMWF model, in the upper stratosphere and lower mesosphere. Although ECMWF analyses are readily available for these altitudes, observations to assimilate into the ECMWF model are relatively scarce. Hence, to some extent we are nudging toward the ECMWF model rather than real interpolated observations. Given this limitation, our analysis mainly concentrates on the lower stratosphere. Horizontally, we truncated the data from ECMWF from its original resolution of T319 to the T42 resolution of our MA-ECHAM4 runs. Finally, the ECMWF data, which were available on a 6-hourly basis, were interpolated in time to match MA-ECHAM4's time step (900 s). The spin-up time for the nudged model to reach a balanced state corresponding to a particular meteorological episode has been shown to be at most a few days (Jeuken et al., 1996; de Laat et al., 1999).

\section{Experiment setup}

The HF and $\mathrm{CH}_{4}$ tracer fields in MA-ECHAM4 were initialized on 1 September, 1999, but we started our model run one month earlier to spin-up the nudging procedure, allowing all dynamical and physical processes, including wave interactions between the troposphere and the middle atmosphere, to reach a balanced state. The tracer initialization was based upon the zonally averaged data from the HALOE sunset sweep of 7 August to 22 September 1999, which ranged from $73.9^{\circ} \mathrm{N}$ to $63.5^{\circ} \mathrm{S}$. The HALOE data did not fill the full model domain. Vertically, we filled the top layers by extending the highest HALOE data upwards, and the troposphere by prescribing tropospheric values for both species: zero for HF, $1.76 \mathrm{ppmv}$ for $\mathrm{CH}_{4}$, distributed slightly over the two hemispheres by adding a 0.02 ppmv sine function. Between the tropospheric values and the lowest available HALOE data, we performed a straightforward log-pressure interpolation. Horizontally, we interpolated between about 43 and $62^{\circ}$ latitude to fill a data gap in the HALOE sweep, and extrapolated the data from the highest available latitudes towards each pole.

These two tracer fields were then advected from 1 September 1999 to 30 April, 2000. In the troposphere, we accounted for methane emissions by fixing the surface values, and for rainout of HF by including a two-week decay, similar to (Chipperfield et al., 1997). We simulated $\mathrm{CH}_{4}$ loss in the stratosphere and mesosphere with zonally averaged $\mathrm{CH}_{4}$ loss rates from the Mainz 2D model, which includes reactions with $\mathrm{OH}, \mathrm{O}^{1} \mathrm{D}$ and $\mathrm{Cl}$ as well as photolysis (Bergamaschi et al., 1996). Finally, we fixed the highest model values to the top values of the monthly zonally averaged UARS data (Randel et al., 1998), to account for missing chemistry and transport terms at the top of our model. While we included all of these processes and boundary conditions for completeness and to verify whether the passive tracer assumption would hold, sensitivity checks indicated that none of them have a 

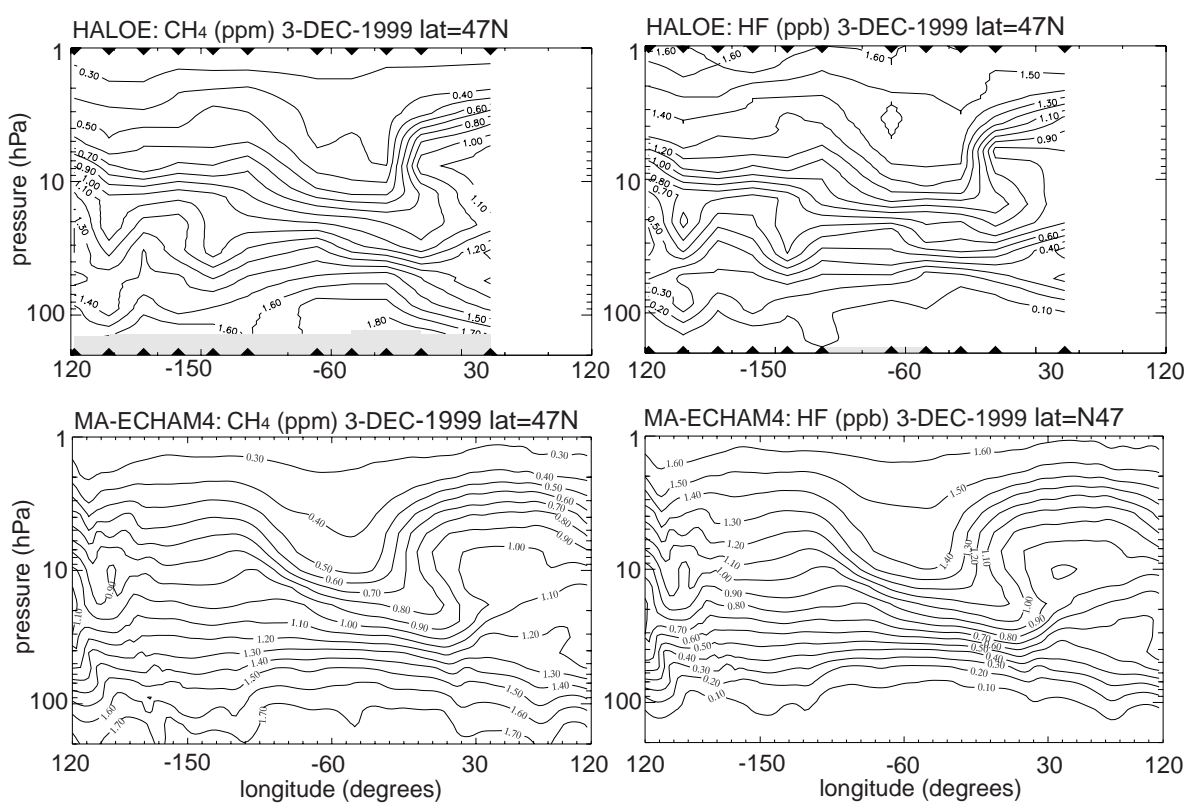

Fig. 2. Longitude versus pressure (from 200 to $1 \mathrm{hPa}$ ) cross-sections of HALOE observations (top) and MA-ECHAM4 fields (bottom) for $\mathrm{CH}_{4}$ (left) and $\mathrm{HF}$ (right) on 3 December, at $47^{\circ}$ latitude.

major impact on the model validation below $20 \mathrm{hPa}$, as will be shown in Fig. 8 .

\section{The Arctic winter 1999-2000}

In 1999-2000, the vortex was already apparent in the upper and mid-stratosphere in early November. It retained a complex structure but became stronger and colder during November and December, and by the end of December it also extended downward into the lower stratosphere, to remain continuously strong and stable during January. In February and over the course of March, upper stratospheric warmings influenced the lower stratospheric circulation, and secondary cold centers developed. Nevertheless, the lower stratospheric vortex remained stable until the end of March, with cold core temperatures. Since the vortex was relatively stable throughout the winter, transport of polar air towards mid-latitudes was less intense than in many other years. However, there were several observations of polar filaments and weak transport, and likely stronger mixing of polar and midlatitude air during the split of the vortex related to the final warming in March. (Manney and Sabutis, 2000; European Ozone Research Coordinating Unit, 2000).

\section{Model results}

Figure 1 shows the zonally averaged $\mathrm{CH}_{4}$ and $\mathrm{HF}$ fields at initialization on 1 September 1999, on 1 December 1999, and on 1 March 2000. The development of the northern win- ter vortex, indicated by a downward movement of the tracer isopleths, can be clearly identified in both HF and methane.

By comparing model data to HALOE profiles in October and November (not shown) we confirmed that the initial initialization was satisfactory. On 3 December, HALOE measured a longitude-altitude cross-section at about $47^{\circ} \mathrm{N}$. These cross-sections, for $\mathrm{CH}_{4}$ and $\mathrm{HF}$, are compared to model data in Fig. 2. This comparison clearly shows that relatively small-scale features, including an intrusion of polar air into the midlatitudes, are well reproduced, both qualitatively and quantitatively. Nevertheless, the model does exhibit some smoothing, probably related to the numerical diffusion of the advection scheme. At that same day, MkIV balloon measurements were performed from Esrange, penetrating the vortex. The left frame of Fig. 3 presents a comparison of these balloon measurements with our model data. The fit is generally good, although there is, already this early in winter, a slight model overestimate of $\mathrm{CH}_{4}$ and underestimate of $\mathrm{HF}$ at about $30 \mathrm{hPa}$.

Furthermore, the model results are generally in good agreement with the profiles that were taken outside of the vortex later in the winter. For instance, the TDLAS-model comparisons in Fig. 4 show that the model fields match the $\mathrm{CH}_{4}$ measurements on 9 February very well. The same agreement was obtained for a number of high latitude HALOE profiles outside of the vortex (not shown). The agreement between the model and the measured profiles was poorer inside the vortex. For 28 January, MA-ECHAM4 overestimates $\mathrm{CH}_{4}$ relative to the TDLAS profile by $0.1-$ $0.3 \mathrm{ppmv}$, with the maximum displacement at $80 \mathrm{hPa}$. Similarly, the MkIV measurements inside the vortex on 15 March 

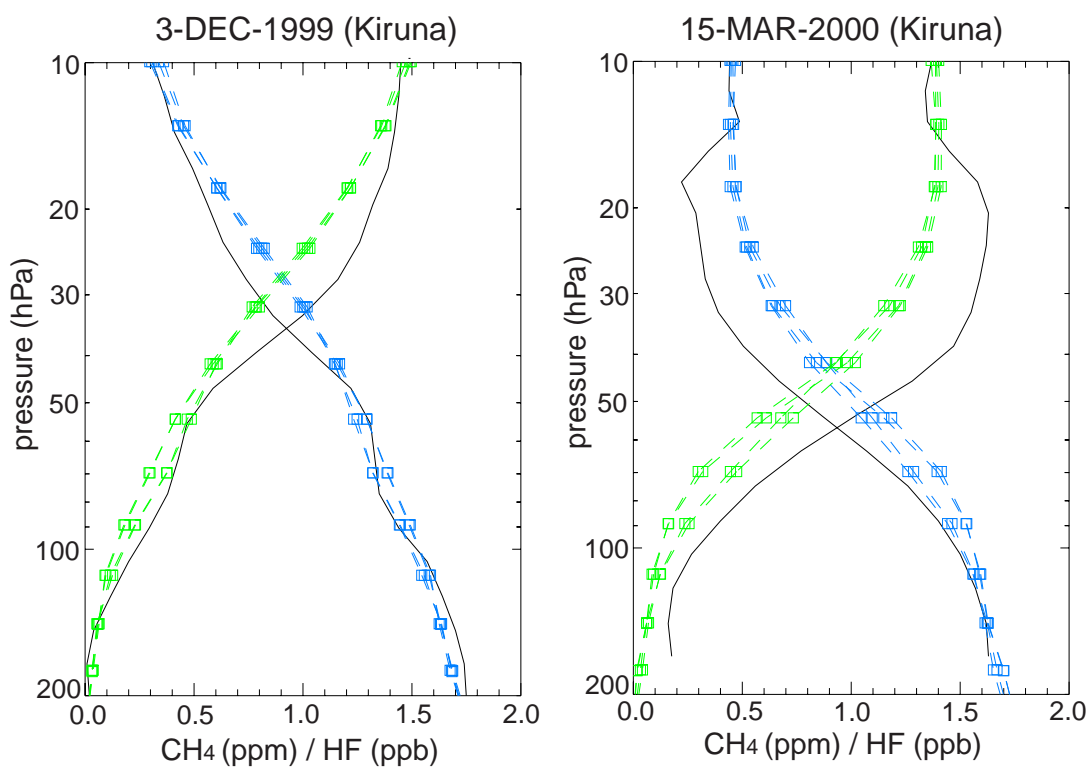

Fig. 3. Concentration versus pressure (from 200 to $10 \mathrm{hPa}$ ) plots of MA-ECHAM4 fields of HF (blue) and $\mathrm{CH}_{4}$ (green) compared to MkIV observations taken from Kiruna (solid) on 3 December and 15 March. Squares represent data at model levels. Model fields were sampled at the four grid boxes surrounding the measurements.

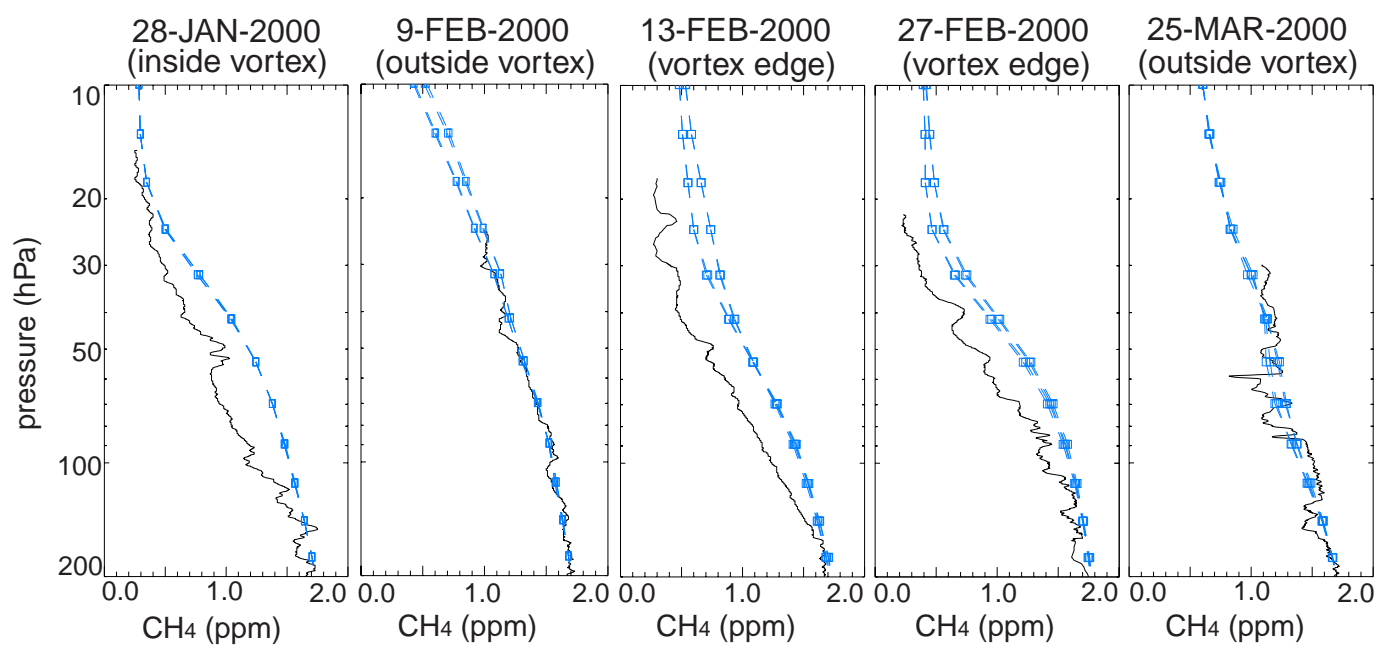

Fig. 4. Concentration versus pressure (from 200 to $10 \mathrm{hPa}$ ) plots of MA-ECHAM4 $\mathrm{CH}_{4}$ results (blue) compared to TDLAS observations taken from Kiruna (solid), on 28 January (inside the vortex), 9 February (outside the vortex), 13 February (inside the vortex, close to the edge), 27 February (inside the vortex, close to the edge), and 25 March (outside the vortex). Squares represent data at model levels. Model fields were sampled at the four grid boxes surrounding the measurements.

show a model underestimate of HF everywhere in the stratosphere up to around $12 \mathrm{hPa}$, with the largest difference of about $0.3 \mathrm{ppb}$ around $25 \mathrm{hPa}$. Interestingly, there is good agreement again around $10 \mathrm{hPa}$. For $\mathrm{CH}_{4}$, there is good agreement up to about $100 \mathrm{hPa}$. At lower pressure levels, the model overestimates the concentrations (by up to $0.3 \mathrm{ppmv}$ at $25 \mathrm{hPa}$ ). As in the case of the HF profiles, the agreement improves again around $10 \mathrm{hPa}$. Potential vorticity maps show that at this altitude (starting around $15 \mathrm{hPa}$ ), the observations were no longer taken inside the vortex but at the mixed edge or even outside it, so that we are really intercomparing midlatitude data. The TDLAS measurements on 13 and 27 February sampled profiles inside the vortex, but close to the edge. Similar to the measurements inside the vortex, the shape of the modeled profiles is realistic, although the model tends to overestimate $\mathrm{CH}_{4}$ in the stratosphere, by about 0.2 ppmv on 13 February and 0.1 ppmv on 27 February. 

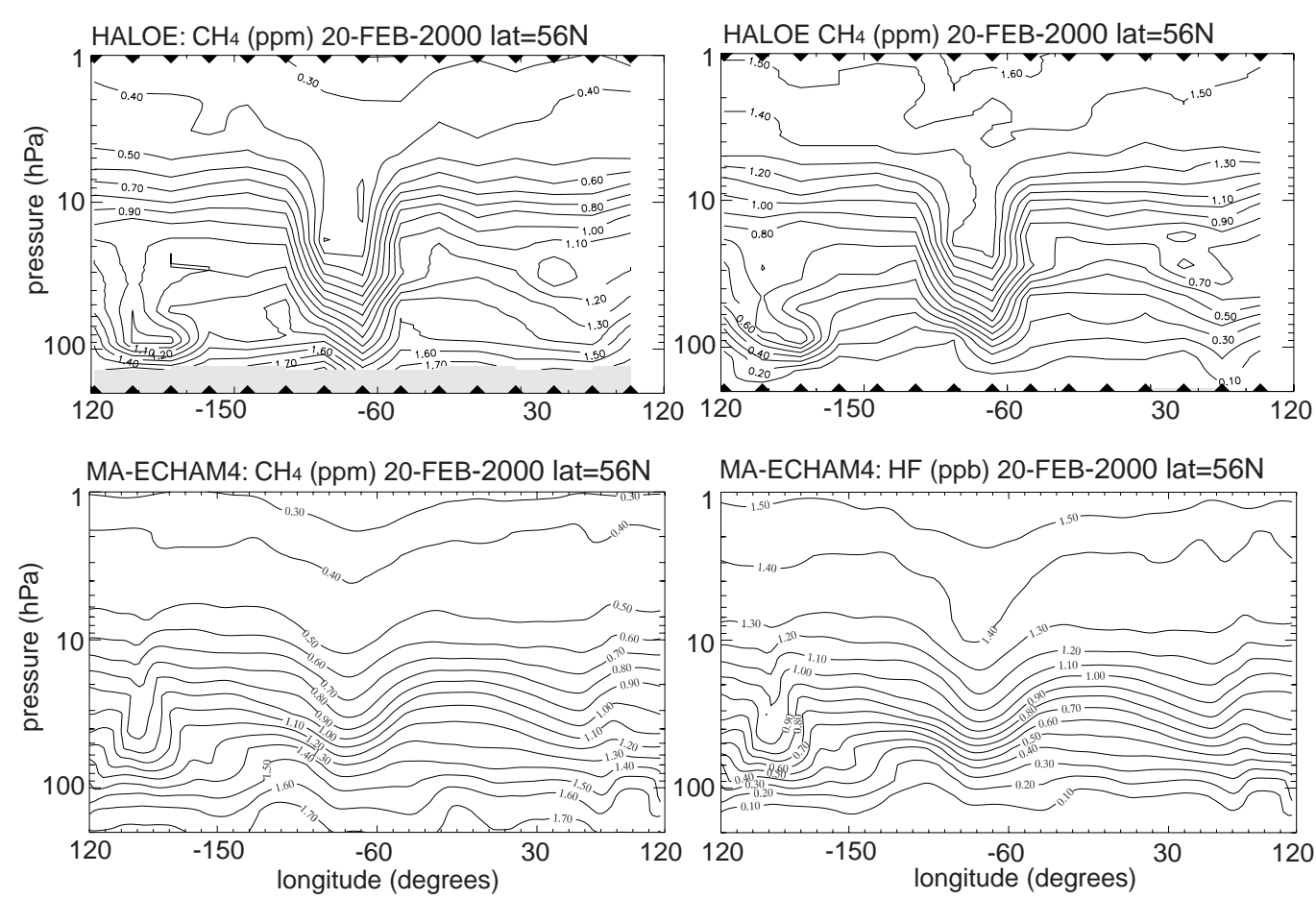

Fig. 5. Longitude versus pressure (from 200 to $1 \mathrm{hPa}$ ) cross-sections of HALOE observations (top) and MA-ECHAM4 fields (bottom) for $\mathrm{CH}_{4}$ (left) and $\mathrm{HF}$ (right) on 20 February, at $56^{\circ}$ latitude.

The difference between the model performance in- and outside the vortex seems to be confirmed by comparing the model results to HALOE data on 20 February. Figure 5 shows a comparison of longitude-altitude profiles at $56^{\circ}$ latitude, cutting through the edge of the vortex at about $80^{\circ} \mathrm{W}$. At this longitude, HALOE clearly sampled vortex air (albeit at the edge of it). Inside the vortex, a similar disagreement appears as in the model-balloon comparisons discussed above. For instance, at $68^{\circ} \mathrm{W}$, we obtain a good match of model and measured $\mathrm{CH}_{4}$ concentrations at $100 \mathrm{hPa}$. However, a difference that increases with altitude appears, up to a substantial model overestimate by about $0.6 \mathrm{ppmv}$ at $20 \mathrm{hPa}$, which decreases again to a small remaining overestimate at $5 \mathrm{hPa}$. For HF, the pattern is roughly reversed, and thus consistent: good fit below $70 \mathrm{hPa}$, a substantial model underestimate above this level that increases with altitude to about $0.4 \mathrm{ppb}$ at $20 \mathrm{hPa}$ and decreases again above $6 \mathrm{hPa}$. Outside the vortex on the other hand, the model tends to overestimate $\mathrm{HF}$ and underestimate $\mathrm{CH}_{4}$. While the discrepancies inside the vortex could be caused by a lack of large-scale descent, which would also be reflected at the edge of the vortex, it is also quite plausible that the model overestimates mixing between vortex and midlatitude air, a phenomenon that would affect vortex edge concentrations relatively strongly. Hence, we have plotted, in Fig. 6, similar longitude-altitude profiles, but now with $3^{\circ}$ increments in latitude, starting at $53^{\circ}$ and ending at $62^{\circ}$ (only HF is shown, $\mathrm{CH}_{4}$ shows a similar pat- tern). These plots clearly show that at $56^{\circ}$, the model does not yet sample "pure" vortex air, since concentration show much steeper gradients at $59^{\circ}$ and $62^{\circ}$ (all at the same longitude of about $80^{\circ} \mathrm{W}$ ). The agreement between vortex profiles from the HALOE measurements at $56^{\circ}$ and the model at $62^{\circ}$ is much better, particularly at higher altitudes. Unfortunately, we can only speculate about what HALOE would have seen at $62^{\circ}$, but these results could indicate that excessive mixing across the vortex edge plays a role in the discrepancies between the model and observations.

Given these anomalies, we have also assessed the model performance with respect to descent during the winter. On each first day of the month, we selected areas in the vortex (using the maximum PV gradients, checked by examining the horizontal wind maximum) and calculated the average vertical profile of the tracer concentrations versus potential temperature. By tracking particular concentration levels as they descended to lower potential temperatures (and ascended again towards the end of the winter), we calculated the descent of the air inside the vortex. These results, based on $\mathrm{CH}_{4}$ profiles, are presented in Table 2 and plotted in Fig. 7. We calculated statistical errors based on the variability in the sample, and found them to be at most a few percent (note that this is the statistical error for the average profile; the variability between individual profiles is of course considerably larger). Very similar results were obtained when we repeated our calculations based on the HF concentrations 

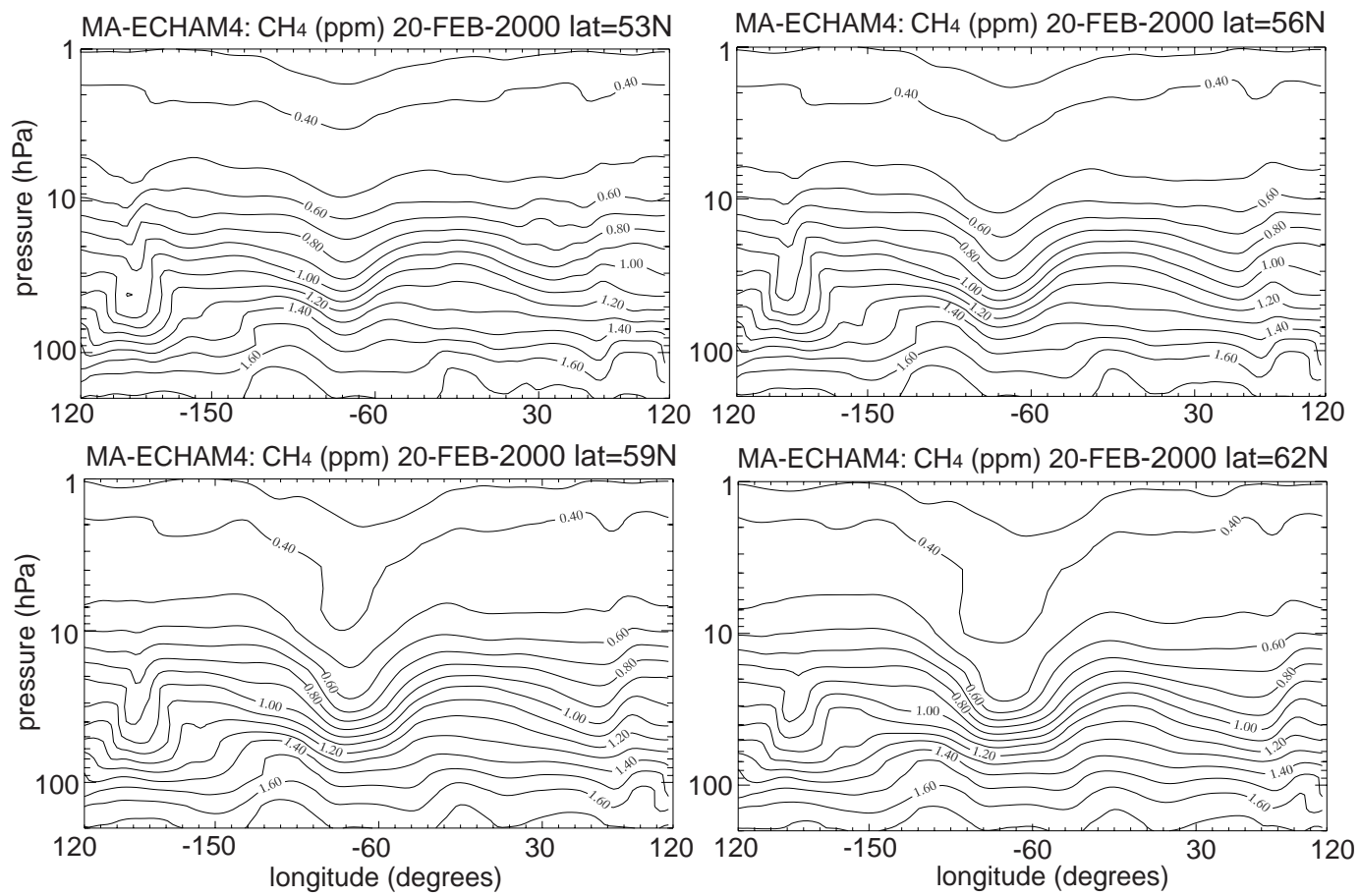

Fig. 6. Longitude versus pressure (from 200 to $1 \mathrm{hPa}$ ) cross-sections of MA-ECHAM4 HF fields on 20 February, at 53, 56, 59, and 62 latitude (to be compared to the HALOE observations in the top right panel of Fig. 5).

Table 2. Descent calculations, based upon MA-ECHAM results for $\mathrm{CH}_{4}$. Descent rates are given in Kelvin per day.

\begin{tabular}{cccccccc}
\hline $\begin{array}{c}\mathrm{CH}_{4} \\
(\mathrm{ppmv})\end{array}$ & $\begin{array}{c}\text { Initial } \mathrm{T}_{\text {pot }} \\
(1 \mathrm{Dec})\end{array}$ & $\begin{array}{c}\mathrm{T}_{\text {pot }} \\
(1 \mathrm{Mar})\end{array}$ & $\begin{array}{c}\text { Average } \\
\text { descent rate } \\
(\mathrm{DJF})\end{array}$ & $\begin{array}{c}\text { Descent } \\
\text { rate Dec }\end{array}$ & $\begin{array}{c}\text { Descent } \\
\text { rate Jan }\end{array}$ & $\begin{array}{c}\text { Descent } \\
\text { rate Feb }\end{array}$ & $\begin{array}{c}\text { Descent } \\
\text { rate Mar }\end{array}$ \\
\hline 0.8 & 619 & 496 & 1.35 & 2.00 & 1.21 & 0.79 & -0.88 \\
1.0 & 557 & 466 & 0.99 & 1.30 & 1.11 & 0.53 & -0.44 \\
1.2 & 498 & 438 & 0.66 & 0.73 & 0.94 & 0.27 & -0.26 \\
1.4 & 435 & 409 & 0.28 & 0.36 & 0.62 & -0.16 & -0.15 \\
1.6 & 370 & 372 & -0.03 & 0.10 & 0.08 & -0.29 & -0.03 \\
\hline
\end{tabular}

in our model. In Fig. 7, we compare our results to similar analyses of $\mathrm{CH}_{4}$ and $\mathrm{N}_{2} \mathrm{O}$ observations by Greenblatt et al. (2002). The match is quite good at higher altitudes (e.g. at early-winter potential temperatures of 500-550 K). Lower in the vortex however, the model descent rate appears to be much lower than observed, consistent with the mismatch in the earlier comparisons between observations and model output.

We have verified that the discrepancies cannot be caused by the lack of full chemistry, or the choice of boundary conditions. First of all, we note that the discrepancies do not occur outside of the vortex. Secondly, we have checked the sensitivity of the model concentrations to changes in the boundary conditions and simplified loss chemistry, and found that at the altitudes of our comparisons, there is very little influ- ence of either the boundary conditions or the chemistry that we included in our sensitivity runs, even for the late winter. A clear example is provided in Fig. 8, where we display the same $\mathrm{CH}_{4}$ balloon-model comparison of 28 January, but now with the passive tracer values (the curve that bends towards the right) and the one used above, which includes methane emissions, a top fixed to the UARS methane climatology, and 2D methane loss rates to account for reactions with $\mathrm{Cl}$, $\mathrm{O}^{1} \mathrm{D}$ and $\mathrm{OH}$ as well as photodissociation. The calculated concentrations only start to diverge above $15 \mathrm{hPa}$. Similar graphs were obtained at other dates and places, indicating that difference between the close match of the two calculated methane tracers at lower altitudes and their divergence at higher altitudes cannot be explained by a temporary and location-specific altitude-related difference in the amount of 


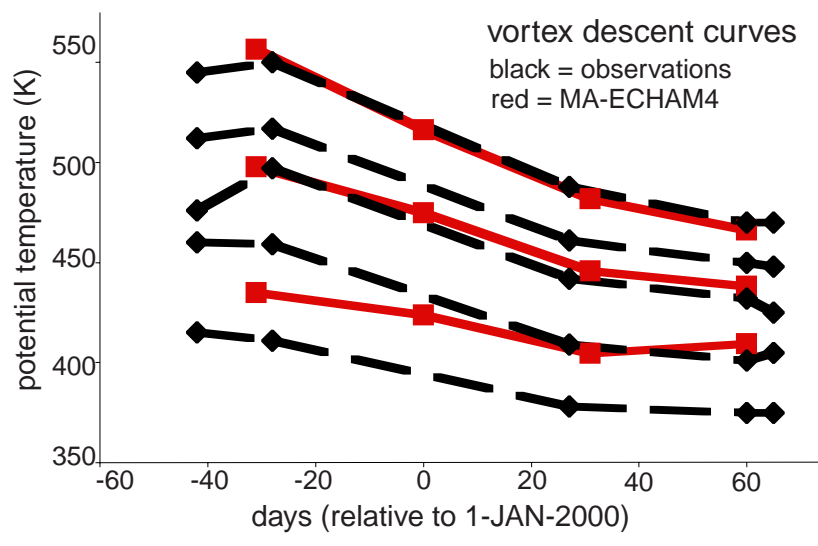

Fig. 7. Vortex descent curves, showing the potential temperature at which various fixed methane concentrations are found through the winter (horizontal: date, relative to 1 January 2000; vertical: potential temperature at which a particular concentration is found at a given date). Solid red: vortex average MA-ECHAM4. Dashed black: individual balloon measurements (Greenblatt et al., 2002). The latter were derived from individual $\mathrm{CH}_{4}$ balloon observations (LACE on 19 November and 5 March, MkIV on 3 December, and BONBON on 27 January and 1 March, respectively).

mixing between inner- and outer-vortex air. Instead, it must be due to the varying influence of chemistry - negligible at lower altitudes, but more important higher up. Given that the differences are negligible below $20 \mathrm{hPa}$, uncertainties with respect to the representation of the chemistry do not affect our model-balloon comparisons.

\section{Discussion}

The general picture emerging from the comparison of our model results with the observations is that the model reproduces relatively small-scale features related to the polar vortex, showing that the nudging procedure enables detailed comparisons between our GCM and individual balloon or satellite measurements. Early in the winter, and later in the winter outside the vortex, the model also exhibits good quantitative agreement with the measurements. However, there is a consistent problem later in the winter inside the vortex, where the model overestimates $\mathrm{CH}_{4}$ and underestimates HF. In comparable experiments with the TM5 chemistry transport "zoom"-model, which was run with the same experimental setup and using the same ECMWF meteorology, Van den Broek et al. (2003) found very similar results. They also showed that a different initialization of the $\mathrm{HF}$ and $\mathrm{CH}_{4}$ fields may lead to better agreement between the model and observations within the vortex, but at the cost of a worse agreement at midlatitudes. Consequently, errors in the HALOE initialization may account for some of the offsets seen in the comparisons, but they cannot explain the discrepancies found in the vertical gradient and over time. Hence, there are only two

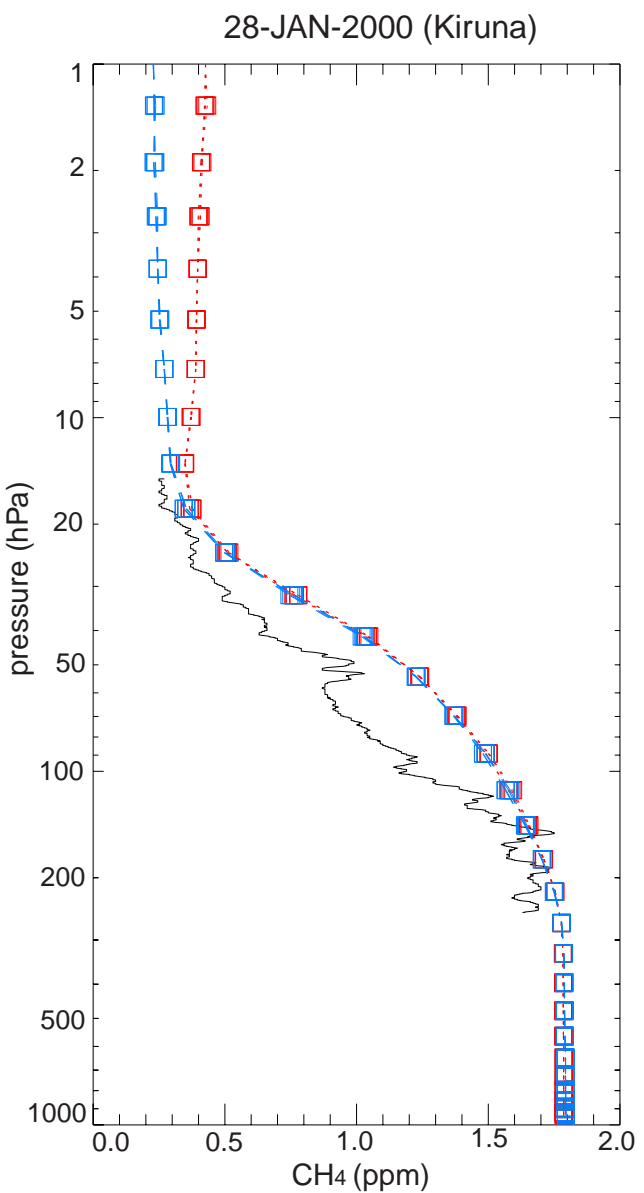

Fig. 8. Concentration versus pressure (from 200 to $10 \mathrm{hPa}$ ) of MAECHAM4 fields of a passive $\mathrm{CH}_{4}$ tracer run (red), and a similar run with methane emissions, chemistry (using 2D loss rates) and top constraints from the UARS climatology (blue), compared to TDLAS balloon measurements (black) on 28 January 2000, inside the vortex.

main options to explain the discrepancies: a lack of descent of air from higher altitudes within the vortex, or an excess of mixing of air across the vortex edge. We note that both of these problems might cause a GCM to overestimate temperatures within the vortex, with potential implications for ozone chemistry.

A lack of descent of air from higher altitudes within the vortex could suggest that such descent is underestimated in the ECMWF fields that we use as input for our nudging procedure. ECMWF's temperatures in the 1999-2000 winter have been shown to be quite close to (both independent and assimilated) observations (Knudsen, 2002; Knudsen et al. 2002). However, the ECMWF may be underestimating the vertical velocity, possibly even while trying to assimilate the correct observed temperatures in a model that may not properly represent all the key processes controlling those temperatures. Then again, the vorticity and divergence should be 
more robust, and these are the variables used in the nudging procedure (along with the temperature and the surface pressure); MA-ECHAM4 itself calculates the vertical velocity and the advection. Another possibility is that the nudging does create a realistic instantaneous meteorology, but also has a small but systematic effect on the descent in the vortex. Given that the vertical velocity is not nudged directly, we have no separate tendency for this effect. Hence, our current experiments did not allow us to test this hypothesis (the best way to test it might be to compare a climate run of several decades with and without nudging). However, we note that the experiments with the TM5 chemistry transport model showed similar problems (van den Broek et al., 2003). In that case, the advection was driven directly by the ECWMF winds, so that the nudging cannot be to blame in their results. Finally, Bregman et al. (2003) point out that errors may arise in the processing of vertical winds from spectral data for advection schemes.

The second possible cause of the discrepancies is an excess of mixing of air across the vortex edge, diluting the air that has descended from higher up. This option seems to be supported by the HALOE-model comparison on 20 February. The TM5 "zoom" model was used to investigate whether such excessive mixing might be caused by the horizontal resolution, which could be too coarse to properly represent the vortex edge (see Van den Broek et al., 2003). Those results show that at $2^{\circ} \times 3^{\circ}$ and even $1^{\circ} \times 1^{\circ}$ horizontal resolution, the descent does not improve. Some of the discrepancies might instead be related to the vertical resolution and coordinate system. In a model with isobaric coordinates, the regular "horizontal" isentropic transport in the stratosphere occurs partly across different isobaric levels. This can cause spurious vertical mixing between levels, particularly when the resolution is too coarse (e.g. Chipperfield et al., 1997, Mahowald et al. 2002). This spurious vertical mixing could also affect mixing across the vortex edge, particularly when the vortex edge is not positioned exactly upright (as is often the case). Finally, Steil et al. (2003) have suggested that the semi-Lagrangian advection scheme employed here also tends to lead to relatively weak downward transport inside the vortex and weak gradients across the vortex edge. In general, this advection scheme results in a relatively high numerical diffusion. In their experiments, Van den Broek et al. (2003) used a mass-flux advection scheme using firstorder slopes (Russell and Lerner, 1993). While it is known that this first-order slopes scheme may also be insufficient to preserve strong gradients (Prather, 1986), the problems should decrease with a higher horizontal resolution. However, their results did not improve when the horizontal resolution was raised, even up to $1^{\circ}$ by $1^{\circ}$.

Future work could include longer runs to study the potential effects of the nudging routine on vertical transport, and tests at higher vertical resolution, or with other advection schemes, such as the Spitfire advection scheme (Rasch and Lawrence, 1998), which is also employed by Steil et al. (2003), or the Lin and Rood advection scheme (Lin and Rood, 1996), which will be incorporated in (MA-)ECHAM5.

\section{Conclusions}

We have nudged the meteorology in our MA-ECHAM4 model towards ECMWF analyses to compare model runs of $\mathrm{HF}$ and $\mathrm{CH}_{4}$, initialized with HALOE data, to balloon and satellite measurements in the SOLVE/THESEO winter 1999/2000. Overall, we find that the nudging procedure, which had not previously been applied in the middle atmosphere, is applicable and allows for a detailed comparison between model output and individual balloon and satellite measurements. It appears that the overall transport patterns around the Arctic vortex are reasonably well modeled. The model reproduces small-scale vortex features, and throughout the winter there is generally good quantitative agreement between the model and the observations, except late in the winter inside the vortex. This may be due to either an underestimate of subsidence in the vortex, or spurious mixing of mid-latitude air into the vortex. An underestimate of subsidence in the vortex could relate to the quality of the ECMWF data or the possibility of small but systematic effects of the nudging on the vertical transport. Spurious mixing could be related to the choice of advection scheme, the current coordinate system, which applies pressure levels in the middle atmosphere, or the processing of the vertical wind field for tracer transport. In any case, these results suggest that care must be taken when studying sensitive chemistry/transport processes in the Arctic vortex with GCMs like MA-ECHAM4.

Acknowledgement. We thank the UARS and HALOE teams for the use of their data, as well as the other members of the TDLAS and MkIV teams, in particular I. H. Howieson, N. R. Swann, and P. T. Woods. We are very grateful to $\mathrm{H}$. Cuijpers (CKO/KNMI) for his excellent ECHAM support, and to I. Kirchner from the Max Plank Institute for Meteorology in Hamburg, who provided the INTERA interpolation package and assisted in setting up the nudging procedure. Finally, we thank the Netherlands Computing Facilities (NCF) Foundation and computing center SARA for use of computing resources.

\section{References}

Austin, J., Shindell, D., Beagley, S. R., et al.: Uncertainties and assessments of chemistry-climate models of the stratosphere, Atmos. Chem. Phys., 3, 1-27, 2003.

Beaver, G. M. and Russell III, J. M.: The Climatology of $\mathrm{HCl}$ and HF Observed by HALOE, Adv. Space Res., 21, 1373-1382, 1998.

Bergamaschi, P., Brühl, C., Brenninkmeijer, C. A. M., Saueressig, G., Crowley, J. N., Grooss, J. U., Fischer, H., and Crutzen, P. $\mathrm{J} .:$ Implications of the large carbon kinetic isotope effect in the reaction of $\mathrm{CH}_{4}+\mathrm{Cl}$ for the $13 \mathrm{C} / 12 \mathrm{C}$ ratio of stratospheric $\mathrm{CH}_{4}$, Geophys. Res. Lett., 23, 2227-2230, 1996. 
Bregman, A., Segers, A., Krol, M., Meijer, E., and van Velthoven, P.: On the use of mass-conserving wind fields in chemistrytransport models, Atmos. Chem. Phys., 3, 447D457, 2003.

Chipperfield, M. P., Lutman, E. R., Kettleborough, J. A., Pyle, J. A., and Roche, A. E.: Model studies of chlorine deactivation and formation of $\mathrm{ClONO}_{2}$ collar in the Arctic polar vortex, J. Geophys. Res., 102, 1467-1478, 1997.

Chipperfield, M. P., Burton, M., Bell, W., et al.: On the use of HF as a reference for the comparison of stratospheric observations and models, J. Geophys. Res., 102, 12 901-12 919, 1997.

Considine, G., Deaver, L., Remsberg, E., and Russell III, J. M.: Analysis of Near-Global Trends and Variability in HALOE HF and $\mathrm{HCl}$ Data in the Middle Atmosphere, J. Geophys. Res., 104, 24 297-24 308, 1999.

Considine, G., Deaver, L., Remsberg, E., and Russell III, J. M.: HALOE Observations of a Slowdown in the Rate of Increase of HF in the Lower Mesosphere, Geophys. Res. Lett., 24, 32173220, 1997.

De Laat, A. T. J., Zachariasse, M., Roelofs, G. J., van Velthoven, P., Dickerson, R. R., Rhoads, K. P., Oltmans, S. J., and Lelieveld, J.: Tropospheric O-3 distribution over the Indian Ocean during spring 1995 evaluated with a chemistry-climate model, J. Geophys. Res., 104, 13 881-13 893, 1999.

European Ozone Research Coordinating Unit: The Northern Hemisphere Stratosphere in the Winter and Spring of 1999/2000, Cambridge, 2001.

Gettelman, A., Holton, J. R., and Rosenlof, K. H.: Mass Fluxes of $\mathrm{O}_{3}, \mathrm{CH}_{4}, \mathrm{~N}_{2} \mathrm{O}$, and $\mathrm{CF}_{2} \mathrm{Cl}_{2}$ in the Lower Stratosphere calculated from observational Data, J. Geophys. Res. 102, 19 149-19159, 1997.

Greenblatt, J. B., Jost, H.-J., Loewenstein, M., et al.: Tracer-based determination of vortex descent in the 1999-2000 Arctic winter, J. Geophys. Res., 107, D20, 8279, doi:10.1029/2001JD000937, 2002.

Hall, T. M., Waugh, D. W. , Boering, K. A., and Plumb, R. A.: Evaluation of transport in stratospheric models, J. Geophys. Res., 104,18 815-18 840, 1999.

Hines, C. O.: Doppler spread parameterization of gravity wave momentum deposition in the middle atmosphere. Part 1: Basic formulation, J. Atmos. Solar Terr. Phys., 59, 371-386, 1997a.

Hines, C. O.: Doppler spread parameterization of gravity wave momentum deposition in the middle atmosphere. Part 2: Broad and quasi monochromatic spectra and implementation, J. Atmos. Solar Terr. Phys., 59, 387-400, 1997 b.

Jeuken, A. B. M., Siegmund, P. C., Heijboer, L. C., Feichter, J., and Bengtson, L.: On the potential of assimilating meteorological analysis in a climate model for the purpose of model validation, J. Geophys. Res., 101, 16 939-16950, 1996.

Knudsen, B. M.: Updated ECMWF temperature accuracies, poster presentation at the European Ozone Symposium, Gothenburg, 79 September, 2002.

Knudsen, B. M., Pommereau, J.-P., Garnier, A., Nunes-Pnharanda, M., Denis, L., Newman, P., Letrenne, G., and Durand, M.: Accuracy of analyzed stratospheric temperatures in the winter Arctic vortex from infrared Montgolfier long-duration balloon flights. 2. Results, J. Geophys. Res., 107, D20, doi:10.1029/2001JD001329, 2002.

Koshyk, J. N., Boville, B. A., Hamilton, K., Manzini, E., and Shibata, K.: Kinetic energy spectrum of horizontal motions in middle-atmosphere models, J. Geophys. Res., 104, 27 17727 190, 1999.

Lin, S. J. and Rood, R.: Multi-dimensional flux-form semiLagrangian transport schemes, Mon. Weather Rev., 124, 20462070, 1996.

Liu, X., Murcray, F. J., Murcray, D. G., and Russell III, J. M.: Comparison of $\mathrm{HF}$ and $\mathrm{HCl}$ Vertical Profiles from Ground-Based High-Resolution Infrared Solar Spectra with Halogen Occultation Experiment Observations, J. Geophys. Res., 101, 10175 $10182,1996$.

Luo, M., Cicerone, R. J., and Russell III, J. M.: Analysis of Halogen Occultation Experiment $\mathrm{HF}$ Versus $\mathrm{CH}_{4}$ Correlation Plots: Chemistry and Transport Implications, J. Geophys. Res., 100, 13 927-13 937, 1995.

Mahowald, N. M., Plumb, R. A., Rasch, P. J., del Corral, J., Sassi, F., and Heres, W.: Stratospheric transport in a 3dimensional isentropic coordinate model, J. Geophys. Res, 107, D15, 2001JD1313, 2002.

Manney, G. L. and Sabutis, J. L.: Development of the polar vortex in the 1999-2000 Arctic winter stratosphere, Geophys. Res. Lett., 27, 2589-2592, 2000.

Manzini, E. and Feichter, J.: Simulation of the SF6 tracer with the middle atmosphere MAECHAM4 model: Aspects of the largescale transport, J. Geophys. Res., 104, 31 097-31 108, 1999.

Manzini, E. and McFarlane, N. A.: The effect of varying the source spectrum of a gravity wave parameterization in a middle atmosphere general circulation model, J. Geophys. Res., 103, 31523 $31539,1998$.

Manzini, E., McFarlane, N. A., and McLandress, C.: Impact of the Doppler spread parameterization on the simulation of the middle atmosphere circulation using the MA/ECHAM4 general circulation model, J. Geophys. Res., 102, 25 751-25 762, 1997.

Manzini, E., Steil, B., Brühl, C., Giorgetta, M. A., and Krüger, K.: A new interactive chemistry-climate model: 2 . Sensitivity of the middle atmosphere to ozone depletion and increase in greenhouse gases and implications for recent stratospheric cooling, J. Geophys. Res., 108, D14, 4429, doi:10.1029/2002JD002977, 2003.

McFarlane, N. A.: The effect of orographically exited gravity wave drag on the general circulation of the lower stratosphere and troposphere, J. Atmos. Sci., 44, 1775-1800, 1987.

Müller, R., Grooss, J.-U., McKenna, D. S., Crutzen, P. J., Brühl, C., Russell III, J. M., and Tuck, A. F.: HALOE Observations of the Vertical Structure of Chemical Ozone Depletion in the Arctic Vortex During Winter and Early Spring 1996-1997, Geophys. Res. Lett., 24, 2717-2720, 1997.

Nedoluha, G. E., Siskind, D. E., Bacmeister, J. T., Bevilacqua, R. M., and Russell III, J. M.: Changes in Upper Stratospheric $\mathrm{CH}_{4}$ and $\mathrm{NO}_{2}$ as measured by HALOE and Implications for Changes in Transport, Geophys. Res. Lett., 25, 987-990, 1998.

Park, J. H. , Russell III, J. M., Gordley, L. L., Drayson, S. R., Chris Benner, D., McInerney, J., Gunson, M. R., Toon, G. G., Sen, B., Blavier, J.-F., Webster, C. R., Zipf, E. C., Erdman, P., Schmidt, U., and Schiller, C.: Validation of Halogen Occultation Experiment $\mathrm{CH}_{4}$ Measurements from the UARS, J. Geophys. Res., 101, $10183-10203,1996$.

Pawson, S., Kodera, K., Hamilton, K., et al.: The GCM-Reality Intercomparison Project for SPARC: Scientific Issues and Initial Results, Bull. Am. Meteorol. Soc., 81, 2000. 
Plumb, R. A., Heres, W., Neu, J. L., Mahowald, N., del Corral, J., Toon, G. C., Ray, E., Moore, F., and Andrews, A. E.: Global tracer modeling during SOLVE: high latitude descent and mixing, J. Geophys. Res., 107, 8309, doi:10.1029/2001JD001023, 2002.

Randel, W. J., Wu, F., Russell III, J. M., Roche, A., and Waters, J. W.: Seasonal Cycles and QBO Variations in Stratospheric $\mathrm{CH}_{4}$ and $\mathrm{H}_{2} \mathrm{O}$ observed in UARS HALOE Data, J. Atmos. Sci., 55, 163-185, 1998.

Rasch, P. J., Boville, B. A., and Brasseur, G. P.: A threedimensional general circulation model with coupled chemistry for the middle atmosphere, J. Geophys. Res., 100, 9041-9071, 1995.

Rasch, P. J. and Williamson, D. L.: On shape-preserving interpolation and semi-Lagrangian transport, SIAM, J. Sci. Stat. Comput., 11, 656-687, 1990.

Rasch, P. J. and Lawrence, M.: Recent development in transport methods at NCAR. MPI-Report No. 265, Max-Planck-Institut für Meteorologie, FRG, 65-75, 1998.

Ray, E. A., Moore, F. L., Elkins, J. W., Hurst, D. F., Romashkin, P. A., Dutton, G. S., and Fahey, D. W.: Descent and mixing in the 1999-2000 northern polar vortex inferred from in situ tracer measurements, J. Geophys. Res., 107, D20, 2001JD000961, 2002.

Rex, M., Salawitch, R. J., Harris, N. R. P., et al.: Chemical depletion of Arctic ozone in winter 1999/2000, J. Geophys. Res., 107, D20, 8269, doi:10.1029/2001JD000620, 2002.

Roeckner, E., Arpe, K., Bengtsson, L., Christoph, M., Claussen, M., Dümenil, L., Esch, M., Giorgetta, M., Schlese, U., and Schulzweida, U.: The atmospheric general circulation model ECHAM4: Model description and simulation of present-day climate. MPI Rep. 218, Hamburg, Germany, 1996.

Russell, G. M. and Lerner, J. A.: A new finite-differencing scheme for the tracer transport equation, J. Appl. Meteorol., 20, 14831498, 1993.

Russell III, J. M., Deaver, L. E., Luo, M., Cicerone, R. J., Park, J. H., Gordley, L. L., Toon, G. C., Gunson, M. R., Traub, W. A., Johnson, D. G., Jucks, K. W., Zander, R., and Nolt, I.: Validation of Hydrogen Fluoride Measurements made by the HALOE Experiment from the UARS Platform, J. Geophys. Res., 101, $10163-$ $10174,1996$.
Russell III, J. M., Gordley, L. L., Park, J. H., Drayson, S. R., Hesketh, D. H., Cicerone, R. J., Tuck, A. F., Frederick, J. E., Harries, J. E., and Crutzen, P. J.: The Halogen Occultation Experiment, J. Geophys. Res., 98, 10777-10 797, 1993.

Shindell, D. T., Miller, R. L., Schmidt, G. A., and Pandolfo, L.: Simulation of recent northern winter climate trends by greenhouse-gas forcing, Nature, 399, 452-455, 1999.

Shindell, D. T., Rind, D., and Lonergan, P.: Increased polar stratospheric ozone losses and delayed eventual recovery owing to increasing greenhouse-gas concentrations, Nature, 392, 589-592, 1998.

Shindell, D. T., Schmidt, G. A., Miller, R. L., and Rind, D.: Northern Hemisphere winter climate response to greenhouse gas, ozone, solar, and volcanic forcing, J. Geophys Res, 106, 71937210, 2001.

Steil, B., Dameris, M., Brühl, C., Crutzen, P. J., Grewe, V., Ponater, M., and Sausen, R.: Development of a chemistry module for GCMs: first results of a multi-annual integration. Ann. Geophys., 16, 205-228, 1998.

Steil, B., Brühl, C., Manzini, E., Crutzen, P. J., Lelieveld, J., Rasch, P. J., Roeckner, E., and Krüger, K.: A new interactive chemistry climate model. I: Present day climatology and interannual variability of the middle atmosphere using the model and 9 years of HALOE/UARS data, J. Geophys. Res., 108, D9, 4290, doi:10.1029/2002JD002971, 2003.

Toon, G. C.: The JPL MkIV Interferometer, Optics and Photonics News, 2, 19-21, 1991.

Toon, G. C., Blavier, J.-F., Sen, B., et al.: Comparison of MkIV balloon and ER-2 aircraft measurements of atmospheric trace gases, J. Geophys Res., 104, 26 779-26 790, 1999.

Van den Broek, M. M. P., van Aalst, M. K., Bregman, A., Krol, M., Lelieveld, J., Toon, G. C., Garcelon, S., Hansford, G. M., Jones, R. L., and Gardiner, T. D.: : The impact of model grid zooming on tracer transport in the 1999/2000 Arctic polar vortex, Atmos. Chem. Phys., 3, 1833-1847, 2003. 